\title{
KEBIJAKAAN POLITIK PENDIDIKAN YANG MERAKYAT
}

\author{
Oleh : Tim Kerja
}

\section{A. Pendahuluan}

Pendidikan sebagai pilar bangsa merupakan cita-cita pendahulu kita semenjak negara ini diberdirikan oleh para pahlawan, perjuangan untuk mencapai kemerdekaan bukan dimulai dengan letusan senapan api sebagaimana yang dikonstruksikan lewat film-film bersejarah, namun sebaliknya kemerdekaan itu diawali dengan pendidikan. Kita sebut saja, Kartini, Cokroaminoto, Ki Hajar Dewantara dan lain-lain. Mereka adalah tonggak kemerdekaan yang mampu menjadi inspirasi perjuangan bagi bangsa Indonesia. Lewat sejarah kita bisa membuktikan bahwa pendidikan adalah senjata utama untuk merebut kemerdekaan, karena lewat pendidikan orang mulai berpikir, merencanakan dan orang akan berusaha untuk mencapai tujuannya, lewat bekal yang ada di pikirannya. Sebab pendidikan mampu membangkitkan kesadaran seseorang untuk melihat kehidupannya yang terjadi saat itu.

Pendidikan adalah instrument penting dalam membangun karakter bangsa (nation character building). Disadari atau tidak, pendidikan juga merupakan investasi jangka panjang suatu masyarakat-bangsa agar dapat melangkah lebih baik menuju kehidupan yang lebih beradab (civilized). Ibnu Khaldun mengatakan ;

"hanya di dalam realitas masyarakat yang memiliki kesadaran akan pentingnya perkembangan ilmu pengetahuan dan pendidikan, maka peradaban dan nilainilai budaya konstruktif akan dapat ditegakkan."

Dalam konteks ini, pendidikan tidak hanya dimaknai sebagai trans-fer of knowladge semata, akan tetapi yang lebih mendasar ialah bahwa pendidikan merupakan lokomotif dan dinamisator dalam perubahan masyarakat-bangsa ${ }^{1}$

Perkembangan pendidikan seharusnya searah dengan perkembangan kehidupan bernegara, selarasnya pendidikan menjadi nadir atas tumbuh kembangnya sebuah peradaban, kita bisa belajar dari Jepang, jerman dan bahkan dengan Vietnam sekalipun. Bahwa pendidikan menjadi awal tumbuh kembangnya mereka dari

\footnotetext{
${ }^{1}$ Ahmad Tarmiji, Meretas Jalan Sosiologi Pendidikan Ibnu Khaldun: Antara Pendidikan Karakter dan Pendidikan Nasionalisme, Komunitas, 2014.
} 
keterpurukan yang terjadi sebelumnya. Sebaliknya bangsa kita yang terlalu berpikir industrialized sampai lupa untuk memperkokoh pondasi dari struktur pembangunan yang namanya pendidikan.

\section{B. Konseptual Pendidikan di Indonesia}

Historisme pendidikan bangsa Indonesia adalah hasil dan pengaruh dari politik etis, dimana pengaruh politik etis dalam bidang pengajaran dan pendidikan sangat berperan sekali dalam pengembangan dan perluasan dunia pendidikan dan pengajaran di Hindia Belanda. Salah seorang dari kelompok etis yang sangat berjasa dalam bidang ini adalah Mr. J.H. Abendanon (1852-1925) yang Menteri Kebudayaan, Agama, dan Kerajinan selama lima tahun (1900-1905). Sejak tahun 1900 inilah berdiri sekolah-sekolah, baik untuk kaum priyayi maupun rakyat biasa yang hampir merata di daerah-daerah.

Sementara itu, dalam masyarakat telah terjadi semacam pertukaran mental antara orang-orang Belanda dan orang-orang pribumi. Kalangan pendukung politik etis merasa prihatin terhadap pribumi yang mendapatkan diskriminasi sosial-budaya. Untuk mencapai tujuan tersebut, mereka berusaha menyadarkan kaum pribumi agar melepaskan diri dari belenggu feodal dan mengembangkan diri menurut model Barat, yang mencakup proses emansipasi dan menuntut pendidikan ke arah swadaya. ${ }^{2}$

Melanjutkan apa yang telah dicapai sebelumnya, pemerintah dengan berbgai regulasi terus berusaha untuk melindungi serta mengembangkan pendidikan, di dalam pembukaan Undang-Undang Dasar (UUD) Negara Republik Indonesia Tahun 1945 dinyatakan bahwa salah satu tujuan Negara Kesatuan Republik Indonesia (NKRI) adalah mencerdaskan kehidupan bangsa. Sejalan dengan pembukaan UUD itu, batang tubuh konstitusi tersebut di antaranya Pasal 20, Pasal 21, Pasal 28 C ayat (1), Pasal 31, dan Pasal 32, juga mengamanatkan bahwa pemerintah mengusahakan dan menyelenggarakan satu sistem pendidikan nasional dan memajukan kebudayaan nasional untuk meningkatkan keimanan dan ketakwaan kepada Tuhan Yang Maha Esa serta akhlak mulia dalam rangka mencerdaskan kehidupan bangsa yang diatur dengan undang-undang. ${ }^{3}$

\footnotetext{
${ }^{2}$ Wikipedia, Politik Etis. 2014

${ }^{3}$ Rencana Strategis Kementrian Pendidikan Dan Kebudayaan 2014
} 
Pendidikan diupayakan berawal dari manusia apa adanya (aktualisasi) dengan mempertimbangkan berbagai kemungkinan yang apa adanya (potensialitas), dan diarahkan menuju terwujudnya manusia yang seharusnya atau manusia yang dicitacitakan (idealitas). Tujuan pendidikan itu tiada lain adalah membentuk manusia yang beriman dan bertaqwa kapada Tuhan Yang Maha Esa, berakhlak mulia, sehat, cerdas, berperasaan, berkemauan, dan mampu berkarya; mampu memenuhi berbagai kebutuhan secara wajar, berkepribadian, bermasyarakat dan berbudaya. Implikasinya, pendidikan harus berfungsi untuk mewujudkan (mengembangkan) berbagai potensi yang ada pada manusia dalam konteks dimensi keberagaman, moralitas, moralitas, individualitas/personalitas, sosialitas dan keberbudayaan secara menyeluruh dan terintegrasi. Dengan kata lain, pendidikan berfungsi untuk memanusiakan manusia.

Dalam masyarakat, mau tidak mau pendidikan yang berkualitas harus dibentuk oleh pemerintah. Pendidikan harus menjadi ranah yang mudah dijangkau oleh siapa pun di republik ini. Omong kosong jika pemerintah bercita-cita menegakkan hak asasi manusia di negara kita, jika pendidikan masih menjadi second opinion bagi pemerintah dalam mengeluarkan kebijakan. Membangun negara melalui pendidikan yang ramah bagi semua tidaklah rugi. Masyarakat yang akan tercipta adalah masyarakat dengan tahap saling menghormati tiap hak yang melekat pada diri individu dan meningginya sikap toleransi ${ }^{4}$

Harapan tentang bagaimana semua orang bisa merasakan pendidikan, bisa mendapatkan hak pendidikannya maka seharusnyalah pemerintah sudah memikirkan pendekatan pendidikan yang merakyat yang nantinya akan dibahas pada bagian selanjutnya.

\section{Belajar Dari Universitas Di Perancis}

Pikiran tak pernah muncul dari ruang kosong. Ia bukanlah hasil creatio ex nihilo yang seolah vakum dari sejarah, dari relasi-relasi sosial, dan sekonyong-konyong hadir dengan penuh gegap gempita. Pikiran mesti dilihat sebagai ekspresi dari relasi antar berbagai prakondisi material: situasi sosial-politik-ekonomi, konfigurasi sejarah

\footnotetext{
${ }^{4}$ http://www.suarakarya-online.com/news.html?id=189711
} 
dan akhirnya juga institusi, baik dalam arti formal (universitas) dan informal (café, salon des artistes).

Pertama-tama kita lihat Universitas Paris atau apa yang dikenal sebagai Sorbonne. Universitas Paris didirikan pada tahun 1200 oleh Raja Philippe-Auguste dan didukung melalui dekrit kepausan oleh Paus Gregorius IX pada tahun 1231 yang mencakup empat fakultas: teologi, hukum, kedokteran sebagai fakultas utama, dan kesenian sebagai fakultas rendah. Pada tahun 1257, penasihat Raja Louis IX, Robert de Sorbon, mendirikan fakultas khusus untuk para pelajar teologi yang miskinkampus inilah yang nantinya dikenal sebagai Sorbonne. Oleh karena kampus tersebut perlahan-lahan meraih posisi politik yang kuat, maka semenjak abad ke-15 keseluruhan universitas Paris dikenal sebagai Sorbonne.

Pada masa itu, fakultas teologi di Sorbonne memegang peran politik yang kuat dengan hak untuk menyensor atas nama Raja dan Paus. Kekuatan politik ini sebegitu efektifnya sampai-sampai seorang filsuf sekaliber René Descartes, ketika ia menerbitkan bukunya yang dianggap sebagai tonggak kelahiran filsafat Modern, Meditasi tentang Filsafat Pertama, merasa perlu untuk 'minta restu' dari dekan dan para doktor 'fakultas suci Teologi di Paris' dan mempersembahkan karyanya itu kepada mereka seraya memohon patronase ${ }^{5}$

Di luar 'Sorbonne' atau Universitas Paris, terdapat institusi pendidikan lain yang paling bergengsi di kalangan intelektual filsafat Prancis. Institusi itu tak lain adalah École Normale Supérieure (ENS). Institusi ini adalah salah satu dari sederet 'Sekolah-Sekolah Besar' (Grandes Écoles) yang muncul dari tradisi Revolusi Prancis (semuanya didirikan pada masa itu), contoh lain yang cukup terkenal ENS didirikan pada tahun 1794 di rue d'Ulm oleh menteri pendidikan kala itu, Joseph Lakanal, untuk menempa para pelajar sebagai pengajar yang betul-betul menguasai problematika kajiannya sehingga dapat memberikan pelajaran yang terbaik. Para normaliens (sebutan bagi para mahasiswa yang belajar di ENS) tidak memperoleh gelar akademik apapun dan oleh sebab itu mereka mesti juga mengambil program sarjana dan pasca-sarjana di kampus lain. Uniknya, walau tidak menjanjikan gelar apapun, ENS tetap berdiri sebagai sekolah elit dengan standar yang sangat tinggi dan dengan deretan panjang para pendaftar. Di antara para calon mahasiswa yang

\footnotetext{
${ }^{5}$ Martin Suryajaya, Sistem Pendidikan dan Pemikiran Filsafat Prancis Kontemporer, Jurnal Kajian Wilayah, Vol. 2, No. 2, 2011
} 
nantinya menjadi filsuf besar pun, jumlah yang gagal pada ujian pertama cukup banyak; Derrida gagal dalam ujian pertamanya, Foucault pun demikian dan bahkan mesti mengulang kelas persiapan (khâgne) untuk mengikuti ujian, Lyotard gagal dua kali dalam ujiannya dan akhirnya memilih masuk Sorbonne. Minimnya jumlah mahasiswa yang diterima ini disebabkan oleh standar ujian masuk yang memang sangat tinggi. Namun penempaan yang keras dalam ENS ini terbukti membuahkan hasil. Ini terlihat dari fakta bahwa tingginya presentase jumlah para pengajar di Sorbonne yang berasal dari ENS

Institusi ketiga yang layak disoroti di sini adalah Collège de France yang sudah didirikan sejak tahun 1530 oleh Raja François I. Collège ini berbeda dari kampus pada umumnya karena selain ia tak menyediakan gelar apapun bagi yang mengikuti kuliah-kuliahnya dan tidak mengadakan ujian apapun, kepesertaannya pun sepenuhnya terbuka dan bebas biaya. Seluruh masyarakat Prancis boleh datang dan mengikuti kuliah yang diberikan dalam Collège. Institusi ini sangat prestisius bagi kalangan intelektual Prancis karena para anggotanya, yakni pengajar yang diizinkan memberi kuliah dalam Collège, diangkat secara khusus oleh para anggota senior dan hanya intelektual yang dipandang telah benar-benar mencapai puncak penguasaan atas bidangnyalah yang dipilih menjadi anggota. Alan Schrift mencatat bahwa peran Collège terutama bersifat kultural, atau dengan kata lain, non-akademik (Schrift 2006: 193). Karena publiknya tersusun dari seluruh lapisan masyarakat Prancis dengan latar belakang yang beragam, maka keuntungan menjadi pengajar di Collège adalah dapat mempengaruhi secara langsung lanskap kebudayaan Prancis secara umum. (Suryajaya, 2011)

\section{Fenomena Pendidikan Tinggi Di Indonesia}

Reformasi pendidikan tinggi tidak terlepas dari tranformasi kekuasan dari sentralisasi ke desentralisasi yang ditandai proses pendelegasiaan wewenang dan tanggung jawab kepada pemerintah daerah kabupaten dan kota, dalam konteks regional dan global, Indonesia menjadi contoh baik terjadinya gerakan transformasi dari sentralisasi kekuasaan menuju desentralisasi khususnya dalam pendidikan.

Pasca tumbangnya orde baru hingga 12 tahun berikutnya, pemerintah Indonesia berencana memberikan ruang yang lebih besar kepada universitas berupa otonomi 
khususnya keuangan. Hal ini sebelumnya penuh didanai oleh keuangan negara. Ini arah baru tercermin dalam penerapan beberapa peraturan hukum (PP No 60 dan 61 Tahun 1999, UU 20/2003 tentang Sistem Pendidikan Nasional).

Dalam HELTS, otonomi universitas didefinisikan sebagai desentralisasi kewenangan pemerintah pusat kepada institusi. Sejalan dengan itu, Welch juga menjelaskan bahwa penerapan Badan Hukum merupakan cermin dari desentralisasi pendidikan di universitas. PTN mendapatkan otonomi dalam banyak aspek pengelolaan universitas, namun mereka juga harus menunjukkan akuntabilitasnya kepada pemangku kepentingan. (Hidayat, 2012)

Status otonom harus dijelaskan sebagai otoritas besar universitas untuk memperbaiki sumber keuangan, sumber daya manusia untuk peningkatan kualitas universitas. Universitas-universitas otonom merupakan elemen penting dari hasil reformasi pendidikan tinggi. Dalam sistem terpusat lama, pemerintah pusat telah mendorong pengembangan kurikulum. Peran pemerintah pusat telah sangat kuat, bahkan dengan standar nasional yang dirancang di tingkat pusat.Sistem universitas mengadopsi standar nasional yang kaku, jika tidak maka tidak bisa diakui oleh otoritas politik dalam hal ini Kementrian Pendidikan dan Kebudayaan. ${ }^{6}$

\section{E. Pengalaman Yang Bisa Dipelajari}

Membandingkan dua situasi yang berbeda bukanlah sesuatu yang mudah, mungkin setiap insan pendidikan akan berharap agar bangsa kita bisa mencontoh apa yang telah terjadi di perancis beberapa waktu yang lalu. Namun perkembangan pendidikan yang terjadi disana merupakan bentuk evolusi dari karakter pendidikan yang berawal tumbuh kembangnya masih didominasi oleh kekuasaan raja hinga tataran strata pendidikan menemukan identitasnya sendiri sebagai lembaga yang menghasilkan sumberdaya manusia yang luar biasa.

Perkembangan pendidikan di Indonesia juga merupakan warisan dari pola konservatif yang mana pada masanya hanya kelas tertentu saja yang mampu mengakses pendidikan tersebut. Terlepas dari itu semua, saat ini pendidikan yang

\footnotetext{
${ }^{6}$ Rakhmat Hidayat, Politik Pendidikan Tinggi Indonesia Pasca Orde Baru: Reformasi Tata Kelola Dalam Perspektif New Public Management, Jurnal Komunitas Volume 6 Nomor 2, Desember 2012.
} 
sementara kita dapatkan adalah sebuah penjewatahan atas apa yang dikonstruksi oleh pemimpin negara.

Sejarah membuktikan di awal republic akan dibentuk hanya kaum feudal yang memiliki kesempatan lebih untuk mengenyam pendidikan, hingga akhirnya orde baru tiba pendidikan pun masih milik mereka yang bermodal. Coba kembali kita pahami apa yang terjadi di masa 1600-1700 di Prancis, kepesertaannya pun sepenuhnya terbuka dan bebas biaya, seluruh masyarakat Prancis boleh datang dan mengikuti kuliah yang diberikan dalam Collège. sekolah bahkan tidak memberikan gelar kepada mahasiswanya karena yang dibentuk bukanlah logika formal namun lebih pada subtansinya ketika seseorang akan memahami apa yang dipelajarinya. Untuk Indonesia masih memiliki karakter sentralis yang sangat kuat untuk pengendalian seluruh system pendidikan, kita contohkan saja ketika universitas harus menerima mahasiswa baru maka yang dipakai adalah ukuran penilaian kolektif. Aturan dasar SNPTN dijadikan rujukan kepada seluruh calon mahasiswa yang mengikuti tes masuk, artinya ada suatu generalisasi penilaian untuk setiap individu yang akan mengakses perguruan tinggi negeri. Maka akan timbul ketidakadilan ketika orang yang selama 12 tahun belajar di Papua harus bersaing memperebutkan jatah bangku kuliah dengan orang Jakarta.

Kita bisa bayangkan orang seperti Derrida, Lyotard, bahkan Foucault harus gagal untuk masuk pada salah satu universitas di Perancis. Penyebabnya bukan pada ketidakmampuan akademik namun system yang memaksa mereka untuk memiliki kompetensi, tentang keahlian yang ingin mereka miliki.

Lebih jauh kita lihat apa yang dihasilkan oleh perguruan tinggi kita? Secara kasat mata bisa kita temui pertanyaan maupun pernyataan berikut ini; Lalu apa yang harus saya kerjakan setelah lulus?, Orang tua akan selalu menanggung beban baik secara lahir dan batin!, Nanti lah kalo ada rejeki saya lanjut S2, Tunggu kalo ada peluang untuk kerja, Entah lah yang jelas saya sudah sarjana!. Hikmah apa yang bisa kita ambil dari pengalaman yang terjadi di Prancis, bahwa bangsa kita masih mengukur pendidikan dengan nominal, kita masih memakai standar angka untuk menilai kualitas peserta didik maka nilai akan selalu menjadi momok dan biaya akan menjadi belenggu. 
Memakai pola dari teori aktif, pandangan yang menekankan pengamatan input pendidikansecara kolektif. Di mana sudut terpenting yang harus diperhatikan oleh sekolah adalah proses kematangan pribadi para siswa yang harus difasilitasi, diakomodasi kebutuhannya dan dibimbing menuju kedewasaan. Oleh karena itu, proporsi organisasi sekolah yang cenderung mekanistis harus dipola menjadi flksibel agar para anggotanya bisa berekspresi dengan optimal. (Ravik, 2008)

\section{KESIMPULAN}

Pada bagian terakhir, ada beberapa perihal yang bisa saya simpulkan, bahwasanya dengan model pendidikan yang masih mendahulukan populis ketimbang subtansi maka kita akan selalu berada pada tataran pragmatis. Ada beberapa usulan yang kiranya bisa kita diskusikan bersama terkait pendidikan dan kajian politik adalah; sudah waktunya Kementrian Pendidikan berdiri sendiri tanpa harus ikut pada cabinet yang sedang berjalan, ini untuk memutus mata rantai dominasi dari penguasa terhadap kebijakan pendidikan. Kedua, adanya regulasi pendidikan yang mengisyaratkan bahwa pendidikan itu asasi dan diberikan hukuman bagi yang melanggar, serta adanya jaminan untuk mendapatkan hak pendidikan bagi setiap rakyat. Ada modulasi pajak khusus yang diarahkan hanya untuk pendidikan, jadi untuk biaya pendidikan tidak akan dipolitisasi oleh Dewan perwakilan rakyat, dan terakhir yaitu mensikronkan antara arah pembangunan pendidikan dengan sumber daya pendidikan.

\section{DAFTAR PUSTAKA}

-2014. Ahmad Tarmiji, Meretas Jalan Sosiologi Pendidikan Ibnu Khaldun: Antara Pendidikan Karakter dan Pendidikan Nasionalisme, Komunitas.

Hidayat, Rakhmat. 2012. Politik Pendidikan Tinggi Indonesia Pasca Orde Baru: Reformasi Tata Kelola Dalam Perspektif New Public Management, Jurnal Komunitas Volume 6 Nomor 2 .

http://ravik.staff.uns.ac.id/2008/06/10/sosiologi-pendidikan/\#more-32 di akses tanggal 20 April 2018

http://www.suarakarya-online.com/news.html?id=189711 di akses tanggal 20 April 2018

Peraturan Pemerintah (PP) Nomor 60 Tahun 1999 tentang Pendidikan Tinggi

Peraturan Pemerintah (PP) Nomor 61 Tahun 1999 tentang Penetapan Perguruan Tinggi sebagai Badan Hukum

Suryajaya, Martin. 2011. Sistem Pendidikan dan Pemikiran Filsafat Prancis Kontemporer, Jurnal Kajian Wilayah, Vol. 2, No. 2.

Tilaar, H.A.R.2012. Perubahan Sosial dan Pendidikan Pengantar Pedagogik Transformatif Untuk Indonesia. Rineka Cipta. Jakarta

Umanailo, M Chairul Basrun. Teknik Praktis Grounded Theory Dalam Penelitian Kualitatif. April 2018. https://doi.org/10.13140/RG.2.2.18448.71689

Umanailo, M Chairul Basrun. Perubahan Sosial di Indonesia:Tradisi Akomodasi dan Modernisasi. March 2018. https://doi.org/10.13140/RG.2.2.23761.22887/1 
Umanailo, M Chairul Basrun. Proses Modernisasi dan Pergeseran Okupasi. March 2018. https://doi.org/10.13140/RG.2.2.19671.78241

Umanailo, M Chairul Basrun. Teknik Praktis Riset Fenomenologi. March 2018. https://doi.org/110.13140/RG.2.2.19320.34563

Umanailo, M. C. B. (2018, April 14). Pierre Bourdieu; Menyikap Kuasa Simbol. https://doi.org/10.17605/OSF.IO/GWH34

Umanailo, M. C. B., Bahasoan, H., ASSAGAF, S. A., Hentihu, I., Nawawi, M., Hamid, I., ... Jumu, L. (2018, April 11). NASKAH AKADEMIK PERLINDUNGAN LAHAN PERTANIAN PANGAN BERKELANJUTAN. https://doi.org/10.17605/OSF.IO/AHP3J

Umanailo, M. C. B., Bula, M., Hentihu, I., Umanailo, R., Ningkeula, E. S., Nawawi, M., ... Hamid, I. (2018, April 12). NASKAH AKADEMIK PEDOMAN ORGANISASI DAN TATA KERJA PEMERINTAH DESA. https://doi.org/10.17605/OSF.IO/2WAKP

Umanailo, M. C. B., Hamid, I., Ningkeula, E. S., Hentihu, I., Nawawi, M., Bula, M., ... Assagaf, S. A. (2018, April 11). NASKAH AKADEMIK TATA CARA PENCALONAN, PEMILIHAN, PENGANGKATAN, PELANTIKAN DAN PEMBERHENTIAN KEPALA DESA. https://doi.org/10.17605/OSF.IO/RWKVT

Umanailo, M. C. B., Nawawi, M., Hentihu, I., Hamid, I., Ningkeula, E. S., Bula, M., ... Assagaf, S. A. (2018, April 11). NASKAH AKADEMIK BADAN PERMUSYAWARATAN DESA. https://doi.org/10.17605/OSF.IO/9WKUH

Umanailo, M. C. B., Umanailo, R., Bahasoan, H., Ningkeula, E. S., Assagaf, S. A., Hamid, I., ... Jumu, L. (2018, April 11). NASKAH AKADEMIK KEUANGAN DESA. https://doi.org/10.17605/OSF.IO/MCAFW 